\title{
Assessment of the quality of products in tourism
}

\author{
Prof. Alberta Tahiri \\ Lecturer at Gjilani College \\ Prof.Dr. Idriz Kovaci \\ Faculty of Applied Sciences, Ferizaj
}

\begin{abstract}
This paper examines the issue of quality assessment of tourism products, as one of the key elements of counntries' touristicoffer in a rapidly changing digital and globalized world. Tourism product is a presentation of a broad cross-section of history, nature, archeology, living culture, ensuring that visitors taking part in the discovery will leave with a lasting impression of the diversity, complexity and beauty of the visited country and its culture. As such, it is a product of quite a particular nature, which derives from the coexistence of a series of different elements interlinked among each other. It is the combinations of interlinkages that enable destinations to offer an individualized "total tourism product" that meets the changing needs of various categories of tourists. Total tourism products are complex and are shaped in different offered through numerous and diverse specific products and services,which may be shaped in many different ways and for which demand exists on a combination of motives, often in conflicting mutual interlinkages. The assessment of the quality of tourism offers is a complex process, which focusses around the tourists. The concept of valorization of tourist sites and attractions is a useful tool in the quality assessment. The harsh completion in the field for tourism calls for application of the total quality management system, which improves the ability of the tourism sector to meet the needs and requirements of the tourists, at minimum costs. Creation and introducing quality standards would be an urgent task, which is the responsibility of both businesses and institutions alike.
\end{abstract}

Keywords: tourism, tourism products, valorization of tourism products, quality of tourism products, quality assessment, total quality management

\section{Introduction}

In today's dynamic and rapidly changing digital world of all-round social changes primarily led by the scientific and technical progress, everyone needs time for rest and recreation. The tourism sector offers numerous and diverse opportunities. An individual's selection of the type of holiday depends on their living standard and income, their living environment, the level of education and interest in culture, etc.

Contemporary tourism is fostered through modern social policies, which ensure the rights to paid annual leave for workers and the fundamental human right to use holiday. In fact, tourism is a dynamic phenomenon that has developed that has developed in parallel with the development of civilization and culture. Its growth has been particularly rapid during the twentieth century as a result of the overall social and economic development, improvement of transportation and communication infrastructure and means, furthering of legislation nd social policies in promoting the right to holiday, as well as the progress in art, education, science, sports, etc. 
According to the United Nations World Tourism Organization (UNWTO), a tourist is consideredanyone who travels abroad, for a period of at least one night but not longer than one year and his/heraim is not to benefit economically'. This includes all those who travel for: rest, amusement, relaxation, visiting family and friends, for business and professional reasons, for health reasons, faith,and pilgrimage.

\section{Problem definition}

Tourism product is a presentation of a broad cross-section of history, nature, archeology, living culture, ensuring that visitors taking part in the discovery will leave with a lasting impression of the diversity, complexity and beauty of the visited country and its culture.

In order to increase their tourism-based income, countries specialize in attracting educated, independent travelers and specialized groups of passengers. Often, their tourism strategies target individuals with income above average, as the demographic segment with a desire and ability to pay for unique products and whose spending patterns maximize the advancement of country's development goals.

Another point of attention of a country seeking to strategically develop tourism, is creating value for tourists in a variety of geographic locations throughout its territory, which:

- offers a great variety of products, strengthening the range and diversity available to visitors;

- creates opportunities for diverse local cultures to express themselves, in particular the customs and traditions of different regions of the country; and

- allows inner-land and rural communities to participate in visits and tourism developments and take advantage of them.

\section{Methodology}

This paper has been developed by using the desk-top research method. The following documents were considered and analyzed:

a) secondary sources of information, such as available scientific literature, research studies on tourism and opinions and analysis of tourism strategic plans;

b) legal and planning documents in the field of tourism and related fields; and

c) scientific research, studies, etc. on general quality management and total quality management.

The management concepts and theories related to quality management were cross-examined with the characteristics of the tourism industry, thus thoroughly examining the meaning, importance and manner of introduction and improvement of quality of tourism products.

\section{Hypotheses}

The fundamental hypothesis that we seek to prove throughout this paper are:

- Development of tourism is defined first and foremost by natural, geographic, cultural and political characteristics, besides adequate development and commitment of the human factor.

- Tourist production constitutes the main instrument of marketing. If it is not properly positioned, other marketing tools cannot come to terms.

Fundamental hypotheses are followed by auxiliary hypotheses that are:

1 "UNWTO technical manual: Collection of Tourism Expenditure Statistics". World Tourism Organization. 1995. p. 10. Retrieved 26 March 2009. 
- Planning, development and placement of products should follow all elements of quality, differentiation and competitive positioning, and should have adequate commercial use in order to make up the commercial offer.

- The more accurate product characteristics are defined (primary, secondary, additional etc.), the better for the optimization of the process of tourism development.

\section{Tourist Product}

Tourism product is a product of quite a particular nature, which derives from the coexistence of a series of different elements interlinked among each other. It is exactly the combination of the different elements and their interlinkage that makes up the completetourism product. It is a compilation of goods and services that meet the demand of tourists during their stay away from their permanent residence. This product is always an "unfinished" one, in stark contrast to all other products, which are always marketed as final and ready-to-use products. Tourism products constantly seek to the versatile and diverse needs of consumers, and those needs cannot be met only by using a tourist service or purchasing a single product.

Form the very moment a customer makes the decision to enjoy tourism, until the moment of their return to their permanent residence, the customer seeks to receive a specifically tailored personal tourist product. These expectations refer to each and every time a customer enjoys tourism, i.e. tourists rarely desire the replication of a tourist product that they had bought and used previously. Seen from the perspective of the buyer,tourist product consists of a number of different special products. How many and which specifics products will be included in the overall comprehensive product depends on the needs, interests, preferences and wished of buyers who make an individual choice.

Thus, tourist products can be seen from different viewpoints and defined in different manners: From the tourists' viewpoint, tourism products include various good and services from which they can pick from in satisfying their individual needs. From the point of view of tourism providers, the tourism product is their concrete product that they offer on the market, which, as explained above, in the eyes of the tourists is just an element of the overall comprehensive tourism product.

In other words, for the consumer, the tourism product is the "total product", with its more or less broad and complex structure, which depends on the following concrete conditions during purchase':

1. Operator's offer that is available;

2. The variety of existing different operators that offer not directly competing services, but rather alternative services that tourists could benefit from; and

3. A set of natural, social and cultural elements.

Thus, this paper uses the term "total tourism product" to denote the combination of all attractive components and factors at a tourist site, through which the customer satisfies their individualized tourist demand.

\section{Products forms and content}

Market development requires a continuous modification of the initial form of tourism products. This is because touristscontinuously seek new types of goods and services, which merge into a single product.

There are five forms of tourist products:

1. Integrated tourist product - the entirety of special products united in a single product;

2. Single product-another form of tourist product found in the tourist market, where the product goes on the market as a certain amount of goods and services and for its producer is considered as unfinished product, intended for tourist consumption;

1Gorica Dr. K., "Marketing of the Albanian tourist market - Economic necessity (monographic study), Tirana 2003 
3. Main tourist product - when a single producer releases a small amount of specific products on the market;

4. Partial tourist product - a tourist product which can be displayed as a form of a single producer,

5. Thorough tourist product - when a product is composed by a number of partial products.

The tourism potential of a country is determined on the basis of the provided offer of all the different types of tourism products.

Tourism product has a complex composition and comprises the following parts':

- Travelling,

- Accommodation,

- Tourist resources (activities), and

- Services.

Travelling can be divided into international transport lines, national and local transport movements within the country. Internal movements are usually under the auspices of the local government units. Drafting and approval of the signal system, based on the traffic plan within the country, which need to ensure, among other, discipline of the transport (vehicles) flow and provide parking places ${ }^{2}$.Investments in road infrastructure, rehabilitation or complete reconstruction of primary and secondary roads are of paramount importance. It is a fact that a good number of tourists travel without using a comprehensive organized package tour and as such they travel almost by the same means that other citizens use.

Accommodationis associated with the quality of services in a given municipality, such as water supply, electricity, telephone, internet service and debris removal ${ }^{3}$. At local levels, accurate touristcensus through accommodation serves as the basis to get the total number of tourists. A good reference point is the tax system, which follows and collects number related to hotel and other providers' accommodation services. As a general rule, it is the obligation of the service provider to keep relevant documentation.

Tourist resources and activitiesis provided as a direct service. The natural and archaeological touristresources with proper infrastructure can add to the cultural offer of a given country. Often, local governments encouragebusinesses and individuals to add to the "core" offer by providing of souvenirs and handicraft products (including silver, woodwork, embroidery, paintings, pottery, basketry, maps, photographs, postcards, etc.) as a reminder of the tourists for their visit. ${ }^{4}$

Services-tourists get in touch with a very large number of service employeesin hotels and motels, restaurants, shops, guides accompanying tourists and ordinary people in the country where tourists stay. These service employees live on the location where tourist products are consumed. Various services usually do not attract or lure tourists itself but the lack of them causes enormous damage. The low level of tourist services creates avoidance. The country can be very attractive but should the tourists not feel good, for example due to lack of hospitality from local people, it can be taken for granted that the tourists will leave or at least will avoid returning to that particular destination. This is an element that affects the growth or decline of tourism. At the same time, the tourist product contains a number of services which tourists may not directly get in touch with, but which indirectly influence the tourist service. Examples of such services include: finance sector, health sector services, the sector of wholesale and retail sales, the utilities sector, the public security sector, etc.

1Gorica Dr. K., "Marketing of the Albanian tourist market - Economic necessity (monographic study), Tirana 2003

2Reilly R., Travel and Tourism Marketing Techniques: Merton House Publishing Co. V.1980

3Reilly R., Travel and Tourism Marketing Techniques: Merton House Publishing Co. V.1980

4M. Gashi : The main components of tourism functions in tourist receptive areas - Prishtina 1989 
The service sector is crucial for tourism development taking into consideration both primary and secondary package offers are of crucial importance. In this regard it has to be mentioned that, generally speaking, rural are better than urban areas with regards to hospitality.

Illustration 1 presents the diverse specific tourism products that form the total tourism offer:

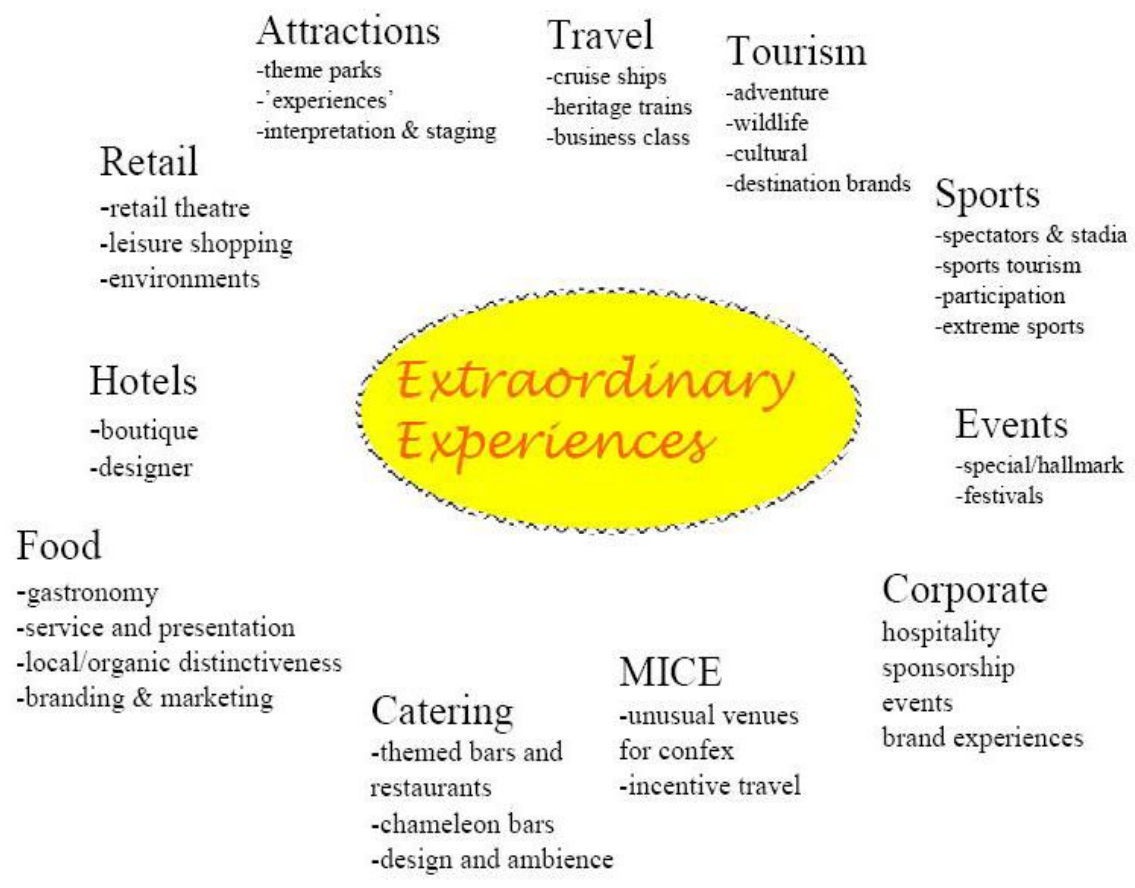

\section{Planning specifications of tourism products}

In comparison to other economic activities, the tourism industry is likely to have fewer opportunities for planning: Tourism product planning largely depends on natural and climatic conditions that are objective and beyond the influence of human will. The planning process is also significantly affected by various social factors, in particular of political and economic nature.Some other factors are: ${ }^{1}$

1. Health circumstances in a country or region;

2. Irrational factors;

3. Administrative constraints;

4. Powerful tourist propaganda;

\section{Prices system.}

All these factors hinder accurate predictions of tourist operations and reduce the possibility of planning in tourism, compared with other economic activities such as industry, construction, transport, etc.

1M. Gashi : The main components of tourism functions in tourist receptive areas - Prishtina 1989 
Product planning in general is possible only at the level of tourist country. Only such a level can fulfill all wishes of a tourist buyer related to their needs while staying in a particular country. It is the responsibility of the country to invest in tourism and attract tourists as purchasers of their natural, cultural, historic, etc. products.

\section{Designing and promotion of tourism products}

Designing a tourism product starts with tourist evaluation. For qualitative and quantitative evaluation of tourist attractions these characteristics should be respected:

- personal activity element;

- geographical position; and

- tourist trade position.

The promotion, which highlights the attractive aspects of products, stimulates the demand and can have the following functions:

- an introductory function for new products;

- selective function, stimulating competition; and

- a function for expanding interests and strengthening affirmed products in the market.

In this regard, one has to stress the extreme importance of international promotion of a country'stourism products.

\section{Assessment of Quality of Tourism Products}

Tourism development is determined primarily by natural and geographic, as well as cultural and political characteristics, complemented by adequate development and commitment of the human factor. Geographically, for example, the most important is the concentration of natural resources and the diversity of supply in a small geographic area.

Tourist production constitutes the main instrument of marketing. If it is not properly positioned, other marketing tools cannot come to terms; rather, they become counterproductive, generally speaking, because of the product itself.

Planning, development and implementation outcomes of the product should contain all the elements of quality, differentiation and competitive positioning, and should have adequate commercial use in order to make up the commercial offer. For this reason it is necessary that product characteristics should be defined more accurately (primary, secondary, supplements, etc.) and the process of development and management of products needs to be optimized.

\section{Valorization}

Valorization represents the determination or assessment of the value of tourist attractions and of their attractiveness. Subject of valorization may be objects, spaces and properties that have attractive characteristics for tourists and through which tourists can satisfy their tourist needs (cultural or recreational). With other words, in the scope of tourist assessment are all individual facilities, events and spaces formed by natural processes or human activities.

The objectives of tourism assessment are as follows:

- tourism value of all individual facilities of a country or area in general;

- estimation of possible tourist visits;

- possible activities in the field of investment by size and type of facilities;

- protection of the space in which we want to develop tourism;

- tourism organization; 
- tourismmarketing etc.

Key to understating the valorization, are two basic categories within tourism: attraction and value. Illustration 2 visually depicts the process of valorization:

attraction $\rightarrow$ valorization $\rightarrow$ value

The most important methods of tourist valorization are methods of combined qualitative and quantitative comparison. The basic principles of this method are:

- it can compare only the tourist attractions of the same type;

- elements upon which comparison will be made, must be defined;

- in the comparison system well known motifs and some other typical motifs should be included; and

- the principle of complementarity can be included in order to involve assessment of motifs of another kind.

A prerequisite for acceptance of tourism value is that a facility should have tourist characteristics, mainly property attractiveness (rare attraction, aesthetic, cultural or historic value, etc.). However, for the property to have a tourist value, it must be capable of meeting tourists' needs.

After assessment of the tourist area, important information is obtained such as:

- what kind of tourism is more suitable for development in the valorized area;

- what is missing with attractive properties, facilities and spaces, so that they increase their tourist value;

- what should be built and how to equip the spaces provided;

- what construction standards should be used and for which customers.

\section{Process of tourist valorization}

For tourist assessment of cultural and historical monuments, the following elements are required: 1

- Geographical tourist position - position in relation to the hometown of tourists, position in relation to traffic and traffic access;

- Artistic value - refers to the evaluation of aesthetic qualities, monumental, rare (rarity) cultural and historical importance;

- Environmental tourist value - basic artistic value. Different kinds of geographical spaces, diversity, nature conservation and regulation of environment are evaluated;

- Tourist attraction and identity - the level of tourist attraction, as well as the level of touristvisits is assessed;

- Building and equipping the space - means the level of development of basic tourism and additional facilities;

- Inclusion in the tourist wealth -assessment of touristic values of complementary motifs of the same destination. This assessment is carried out to determine the comparative and competitive ability with other countries.

\section{Quality of the tourist product}

Quality in tourism or, speaking more widely, the quality in services differs from that of the manufacturing industry. For example, the guest has different requirements from the hotel with three, four or five stars, the top-class restaurant and the common one; therefore the quality in tourism in general means meeting the requirements and what is usually expected from guests ${ }^{2}$.But, one thing remains unchanged, the effort to provide service of higher quality, such that will meet the needs of a modern tourist.

Today quality is defined in two ways:

- quality of a product and service, and

1Dr.F.Ukaj "Promocionidhesegmentetbashkëkohorpromocionalnëturizëm",Peje 2006

2FatosUka "Management of tourist organizations and destinations", 2010 
- quality in terms of the customer.

According to the ISO 9000 standard, quality is an entiretyof attributes and features of a product and service upon which the ability to meet special or ordinary requirements of consumers. All these features of a product and service are standardized.

Quality classification is an indicator of grading and means specific properties and characteristics of a product or service to a certain category, e.g. services in hotels of various categories.

From this derives that:

- quality should be at the core of every activity at present or in the future;

- attempts should be made to introduce better quality for all products - services which constitute the total tourismproduct, as the only manner to make the total product more attractive and refined; and

- in business, there should be a standard which will summarize and standardize the quality of products - services that will help create the image of the tourist offer.

Creation and introducing quality standards would be an urgent task, which is the responsibility of both businesses and institutions alike.

\section{Total Quality Management}

The importance of quality production in contemporary action is vital for operation and existence of all economic enterprises.

Tourism sector is not an exemption in this regard; on the contrary, the competition is so significant and "ruthless" and market demands are increasing on daily basis. Therefore, the need to manage the overall quality is inevitable. Successful quality management techniques become imperative and achievement of qualitative production and service are the key to survival in the market. ${ }^{1}$

The continuous goal is to advance the quality of production and service, through utilization of the Total Quality Management (TQM) system. The main idea behind this system is that the quality is not produced, but managed. For this reason, TQM is totally oriented to the market and is led by the guests, i.e. the tourists because the process begins and ends with them.

This is a cycle consisting of four main activities:

- quality planning;

- implementation of quality;

- assessment of achievements and its improvement; and

- theconstant repeat of the process.

TQM techniques and methods of in hotel activities are as follows: ${ }^{2}$

1. Taking the responsibility for quality (this means developing organizational culture and therefore top-level management in the enterprise should be included).

2. Guest satisfaction should be of main priority (guests always prefer quality and the task of a hotel enterprise is to exceed guest expectations).

3. Control of the enterprise culture (senior management should be evaluated on the enterprise culture and TQM requirements; should the need be, corrections should be made).

1Martínez-Lorente, Angel R.; Dewhurst, Frank; Dale, Barrie G. (1998), "Total Quality Management: Origins and Evolution of the Term", The TQM Magazine

2Martínez-Lorente, Angel R.; Dewhurst, Frank; Dale, Barrie G. (1998), "Total Quality Management: Origins and Evolution of the Term", The TQM Magazine 
4. The degree of individual responsibility and teamwork (TQM process is a bottom-up process and the staff should be educated to influence the management for the benefit of the hotel enterprise).

5. Survey on meeting the quality requirements (TQM process foresees the ability to evaluate efforts to increase individual service, bids, and subsequently the guest satisfaction rate. Precise and simple summary and analysis of the applied techniques will enable to design and implement changes in the organization. It should be noted that TQM relies more on rational choices rather than statistical analysis).

Prerequisites that must be met to ensure quality and establishing quality management system are: ${ }^{1}$

- marketing-orientated organization;

- preparation of programs for quality;

- creation of logistics;

- streamlining overall operations; and

- computerization of work.

The goal of TQM is to achieve the quality of a product and service with minimum costs, to meet the requirements of guests.

This requires overall cooperation by all employees.

Illustration 3 depicts the characteristics of the TQM system:

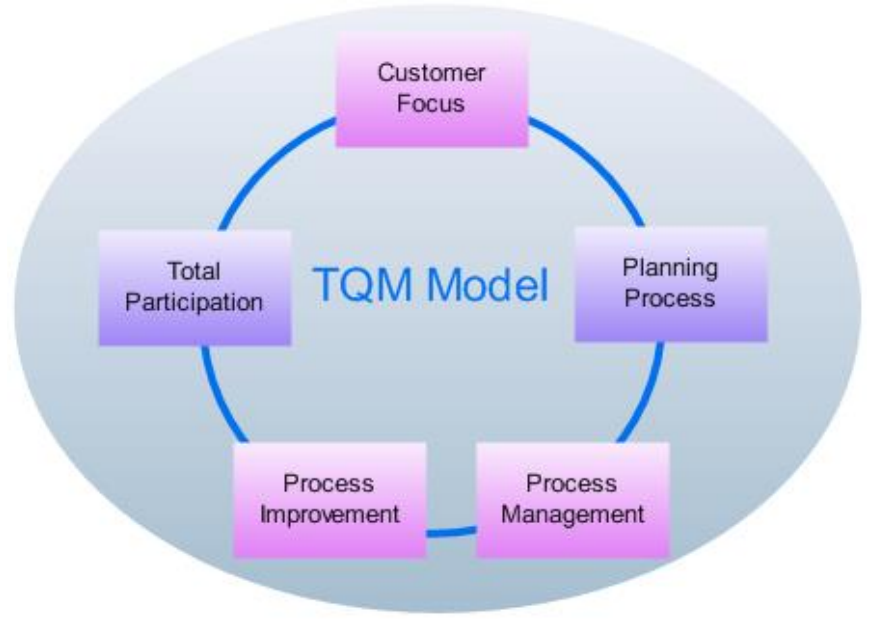

TQM framework application is:2

- values orientation;

- guest orientation;

- staff orientation;

- process and optimal composition; and

- quality control.

The task of TQM is to put guests' requests to be at the center of all activities. In this regard,the central questions are what guests expectas high-quality service and how the company understands their requirements.

Criteria used by experts to define qualityusually are:

1Aslimoski B., Menaxmentnakvalitet,Fakultetzaturizam, Ohrid , 2005.

2Institute for Studies of Organizational-Applied Sciences "Pjetër Budi",Prishtina 
- material criteria(are the guests satisfied from personnel appearance and equipment);

- criteria of devotion and correctness (for the service provided and the payment done);

- criteria of understanding and helping the guest (special care for each guest);

- willingness to help the guest.

The use of TQM system in the service and tourism sector is very important, considering that each and every hotel needs to improve service quality. However, quality management in the hotel sector does not only mean managing the quality of services regarding rooms (accommodation), food and beverages, but also providing other services, which adds to the complexity of the process.

\section{Conclusions}

Undisputed goals of tourism development incorporate the incline towards increasing tourists' pleasure, while simultaneously furthering the well-being of the hosts. The presumptions for successful realization of these goals are permanent consciousness about the ever-changing context on the side of tourism workers and industry, and their attitude to respond to those changes. A country which aims to develop tourism and has such potential should primarily address important general issues:

- ensuring stable economic and political position and improving the image internationally;

- recognition and followingmovements in the tourism market; and

- harmonization of legislation in line with key international standards.

More concretely, countries seeking to advance their tourist offer need to:

- create the basis for geographic linking of tourism with that of their neighboring countries;

- increase visibility and promote tourism development in provincial and rural areas, bringing development opportunities to a broader section of the population;

- permit development of complementary specialized markets for tourism (such as free movement of animals, climbing, diving, agriculture, hunting and fishing, archeology, existing infrastructure and proposed central products of tourism. Forest parks in Albania, for example, create very interesting environment and increase the interests of visitors who adore nature);

- develop local tourism in line with the global criteria and standards.

The destination represents is the primary reason for being interested to travel, whilst tourist products and services enable tourists to make a concrete selection. Due to the inherent nature of tourism consumption, the purchase is made where the holiday package is produced.

Meanwhile, the destination itself comes under pressure from visitors: the more tourists arrive, the greater the pressure upon the destination. To tackle this, carefulprofessional management and destination planning are extremely important if tourism wants to preserve the destination valuable and distinctive elements in the long run, while at the same time preserving its visibility as an "acceptable" tourist offer.

The general characteristics of the tourist offer, the destination, "production" of the holiday offer and heterogeneity of elements are extremely stable.In other words, all destinations are combinationsof fixed variables of factors and opportunities of tourist activities. If one of the factors is missing, then one cannot speak of a tourist destination. Destination problems mostly stem from the lack of coordination and response of various actors.

Tourist travel as a product is a complex productthat is offered through numerous and diverse specific products and services, which may be shaped in many different ways and for which demand exists based on a combination of motives, often in conflictingmutual interlinkages. 
This calls for careful application of the total quality management system in the tourism sector, in all aspects of the design, production, and marketing of a total tourism product as one of the key elements for attracting tourists and boosting tourismrelated income.

\section{References}

[1] A History of Managing for Quality: The Evolution, Trends, and Future Directions of Managing for Quality, Milwaukee, Wisconsin: ASQC Quality Press,

[2] Aslimoski B.,Menaxmentnakvalitet. Fakultetzaturizam, Ohrid , 2005

[3] Dr.F.Ukaj "Promotion and contemporary promotional segments in tourism",Peja 2006,

[4] Gorica Dr. K., "Marketing of Albanian tourist market - Economic Necessity (monographic study), Tirana 2003

[5] Hodson. A.:" The Travel and Tourism Industry-Strategies", PergamonPress,London 1987.

[6] Institute for Studies of Organizative-Applied Sciences"Pjetër Budi"- Prishtina

[7] M. Gashi : The main components of tourism functions in receptive tourist areas-Prishtina 1989

[8] Martínez-Lorente, Angel R.; Dewhurst, Frank; Dale, Barrie G. (1998), "Total Quality Management: Origins and Evolution of the Term", The TQM Magazine

[9] Presentation presented at the International Symposium "PrirodnoiKulturnohistorijskonasljedje I novimodeliupravjanjarazvojemturizma", Vlasic,14-15 March 2008, BiH, “

[10] Total Army Quality Management, Washington, D.C.: United States Army, 1992-06-12, Army Regulation 5-1, retrieved 2013-10-19

\section{Other sources:}

1. http://en.wikipedia.org/wiki/

2. www.visitkosova.org

3. www.kotas-ks.org

4. www.kosovundp.org

5. www.euinkosovo.org

6. www.rugovaexperience.org 